\title{
Association of body mass index with incident tuberculosis in Korea
}

\author{
Soo Jung Kim ${ }^{1}$, Shinhee $\mathrm{Ye}^{2}$, Eunhee $\mathrm{Ha}^{2}$, Eun Mi Chun ${ }^{1 *}$ \\ 1 Division of Pulmonary and Critical Care Medicine, Department of Internal Medicine, College of Medicine, \\ Ewha Womans University, Seoul, Republic of Korea, 2 Department of Occupational and Environmental \\ Medicine, College of Medicine, Ewha Womans University, Seoul, Republic of Korea
}

*cem@ewha.ac.kr

\section{Abstract}

\section{Introduction}

Overweight or obesity might be protective factors of tuberculosis (TB), but the evidence is inconclusive. The objective of study was to evaluate association between BMI and incident TB.

\section{Methods}

The National Health Insurance database was used. Eligible participants were individuals aged 20-89 years without history of TB before 2007, and who underwent national health examinations between January 2002 and December 2006. The latest record of BMI was used as the exposure and categorized as follows: $<18.5,18.5-23,23-25,25-30$, and $\geq 30$ $\mathrm{kg} / \mathrm{m}^{2}$. TB was defined as the first recorded diagnosis of TB, using ICD-10 between January 2007 and December 2013.

Editor: Horacio Bach, University of British Columbia, CANADA

Received: November 6, 2017

\section{Results}

Accepted: March 17, 2018

Among 301,081 individuals, 3,772 (1.26\%) incident TB cases were detected. The incidence rate of the event was 19.65 per 10,000 person-years. After adjusting age, sex, household income, smoking status, alcohol use, and diabetes, incident TB was decreased as BMI was increased in an inverse dose-response relationship. However, when stratified by age and sex, $\mathrm{BMI}>30 \mathrm{~kg} / \mathrm{m}^{2}$ did not show protective effect of TB in female under 50 years. Additionally, BMI $>30 \mathrm{~kg} / \mathrm{m}^{2}$ did not decrease incident TB in diabetics.

\section{Conclusion}

Data Availability Statement: All relevant data are within the paper and its Supporting Information files.

Funding: The authors received no specific funding for this work.

Our study suggests that high BMI might be associated with decreased risk of TB. However, very high BMI did not reduce the risk of TB in young females or diabetics participants with in Korean population.

Competing interests: The authors have declared that no competing interests exist. 


\section{Introduction}

Low body mass index (BMI) is an important risk factor for the development of tuberculosis (TB) [1]. Additionally, there is growing evidence that high BMI is a protective factor of TB. Previous epidemiologic data reported that obesity was associated with reduced risk of active TB in an inverse dose-response relationship [2-5].

However, obesity has also been linked to diabetes mellitus (DM), which is an important risk factor for TB [6]. Furthermore, adipose tissue participates in inflammation and immunity, producing and releasing a variety of pro-inflammatory and anti-inflammatory factors that might influence susceptibility to infections [7]. In one study, BMI above $28 \mathrm{~kg} / \mathrm{m}^{2}$ was independently associated with host susceptibility of TB in rural China [8]. Additionally, although an inverse logarithmic relationship between TB incidence and BMI was showed in another study, the relationship was uncertain at a BMI above $30 \mathrm{~kg} / \mathrm{m}^{2}$ [3].

From the foregoing it is evident that the effect of overweight or obesity, especially a BMI exceeding $30 \mathrm{~kg} / \mathrm{m}^{2}$, on the development of TB is inconclusive. Overweight and obesity might be a protective factor of TB, or a target for TB control. To provide clarity, we investigated the effect of BMI on TB in a Korean population, using a nationwide database from 2002 to 2013. We also performed a stratified analysis to explore whether any specific subgroups were more affected by BMI change.

\section{Methods}

\section{Data source and study design}

The present study was performed between January 1, 2002 and December 31, 2013, using data from the National Health Insurance (NHI) database, which includes a proportionate stratified random sample of individuals who visited hospitals under the NHI program that covers all legal residents of the Republic of Korea. The NHI database contains demographic information, including age, sex, household income, and district level address, and inpatient and outpatient medical care utilization information, including date of service, diagnosed disease based on Tenth Revision of the International Classification of Diseases (ICD-10), prescribed drugs, and medical or surgical procedures performed. The database also includes the health examination results of individuals who participated in free health examination services provided by the NHI. Individuals with lower income and disability have been reported to be less likely to participate in the free health examination compared with those with higher income and without disability. All data was completely anonymous before access.

Eligible participants were individuals who participated in national health examination services between January 1, 2002 and December 31, 2006, and who were aged 20-89 years of age in 2007. Individuals diagnosed as TB before January, 2007 and patients with human immunodeficiency virus (HIV) infection were excluded. Follow-up period was between January 1, 2007 and December 31, 2013.

This study approved by Institutional Review Board (IRB) of Ewha Womans University Medical Center (IRB number: 2016-08-038) and the NHI Service (research management number: NHIS-2016-2-202).

\section{Assessment of BMI}

Of the health examinations data between January 1, 2002 and December 31, 2006, the latest record of BMI was used as the exposure of participants. Individuals were categorized into five BMI groups: $<18.5,18.5$ to $22.9,23.0$ to $24.9,25.0$ to 29.9 , and $\geq 30.0 \mathrm{~kg} / \mathrm{m}^{2}$, as proposed by 
World Health Organization (WHO) for the Western-Pacific region [9] and by the Korean Society for the Study of Obesity [10, 11].

\section{TB outcome}

Incident TB was defined as a first recorded diagnosis of TB based on ICD-10 code (A15.XA19.x) during the follow-up period.

\section{Statistical analysis}

To clarify the characteristics of study population, descriptive analyses were performed using the chi-square test for categorical variables and ANOVA test for continuous variables according to BMI level. The criterion for statistical significance was $\mathrm{p}<0.05$.

A multivariate Cox proportional hazards regression analysis was performed to evaluate the effects of BMI on the incidence of TB. Before the analysis, the assumption of proportionality was confirmed by Schoenfeld residuals. Multivariate Cox proportional hazards model was used adjusted by sex, household income ( $>$ and $<50^{\text {th }}$ percentile), smoking status (never smokers, former smokers, current smokers), alcohol use (never drinker, 2 3/month, 1 2/ week, 3 4/week) and presence or absence of DM, which has been known as risk factors of TB [12-14]. Additional stratified analysis was performed to find whether specific subgroups were more affected by BMI change. All statistical analyses were performed using SAS version 9.3 software (SAS Institute Inc., Cary, NC).

\section{Results}

\section{Study population}

Between January 1, 2002 and December 31, 2006, 313,425 individuals underwent national health examinations (Fig 1). Among them, 12,242 subjects were excluded because they had a

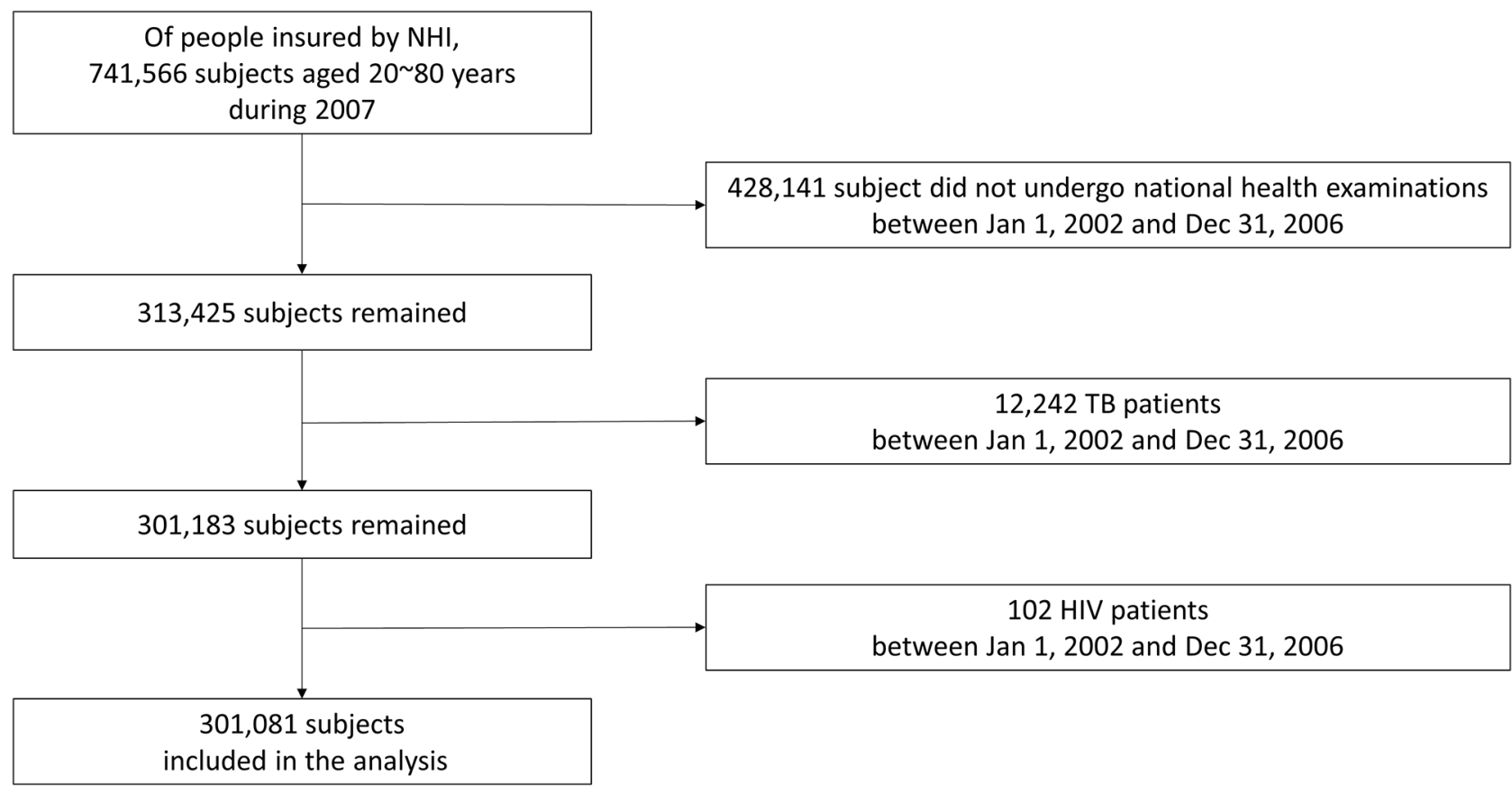

Fig 1. Study population. NHI indicates National Health Insurance; TB, tuberculosis; HIV, human immunodeficiency virus. 
Table 1. Baseline characteristics of the cohort.

\begin{tabular}{|c|c|c|c|c|c|c|}
\hline & \multicolumn{5}{|c|}{ BMI category $\left(\mathrm{kg} / \mathrm{m}^{2}\right)$} & \multirow[b]{2}{*}{ P-value } \\
\hline & $\begin{aligned} & <18.5 \\
(\mathrm{~N} & =11,955)\end{aligned}$ & $\begin{array}{c}18.5 \text { to } 22.9 \\
(\mathrm{~N}=119,813)\end{array}$ & $\begin{array}{l}23.0 \text { to } 24.9 \\
(\mathrm{~N}=74,419)\end{array}$ & $\begin{array}{l}25.0 \text { to } 29.9 \\
(\mathrm{~N}=85,806)\end{array}$ & $\begin{aligned} & \geq 30.0 \\
(\mathrm{~N} & =9,088)\end{aligned}$ & \\
\hline Incidence of $\mathrm{TB}$ & $257(2.1)$ & $1893(1.6)$ & $839(1.1)$ & $720(0.8)$ & $63(0.7)$ & $<0.001$ \\
\hline $\begin{array}{l}\text { Interval from BMI measurement to TB } \\
\text { occurrence, years }\end{array}$ & $4.1 \pm 2.4$ & $4.2 \pm 2.3$ & $4.3 \pm 2.3$ & $4.3 \pm 2.3$ & $4.2 \pm 2.2$ & 0.8470 \\
\hline Age, years & $41.7 \pm 17.1$ & $46.3 \pm 14.5$ & $49.9 \pm 13.2$ & $50.6 \pm 13.0$ & $48.7 \pm 14.0$ & $<0.001$ \\
\hline \multicolumn{7}{|l|}{ Sex } \\
\hline Male & $3754(31.4)$ & $55588(46.4)$ & $44171(59.4)$ & $53683(62.6)$ & $4946(54.4)$ & $<0.001$ \\
\hline Female & $8201(68.6)$ & $64225(53.6)$ & $30248(40.6)$ & $32123(37.4)$ & $414(45.6)$ & \\
\hline \multicolumn{7}{|l|}{ Household income } \\
\hline$<50^{\text {th }}$ percentile & $5,172(43.3)$ & $44383(37.0)$ & $24510(32.9)$ & $27856(32.5)$ & $3,419(37.6)$ & $<0.001$ \\
\hline$\geq 50^{\text {th }}$ percentile & $6,783(56.7)$ & $75430(63.0)$ & $49909(67.1)$ & $57950(67.5)$ & $5,669(62.4)$ & \\
\hline $\mathrm{DM}$ & $146(1.2)$ & $2835(2.4)$ & $2636(3.5)$ & $3874(4.5)$ & $536(5.9)$ & $<0.001$ \\
\hline \multicolumn{7}{|l|}{ Smoking status } \\
\hline Never & $8586(77.8)$ & $78747(72.2)$ & $45391(68.2)$ & $50644(66.5)$ & $5539(67.3)$ & $<0.001$ \\
\hline Former & $241(2.2)$ & $3866(3.5)$ & $3497(5.3)$ & $4322(5.7)$ & $357(4.3)$ & \\
\hline Current & $2204(20)$ & $26501(24.3)$ & $17627(26.5)$ & $21245(27.9)$ & $2330(28.3)$ & \\
\hline \multicolumn{7}{|l|}{ Alcohol use } \\
\hline Never & $6789(58.5)$ & $63254(54.3)$ & $37040(51.3)$ & $41942(50.3)$ & $4746(53.7)$ & $<0.001$ \\
\hline $2 \sim 3 /$ month & $2504(21.6)$ & $23412(20.1)$ & $13396(18.5)$ & $14664(17.6)$ & $1452(16.4)$ & \\
\hline $1 \sim 2 /$ week & $1650(14.2)$ & $20158(17.3)$ & $14664(20.3)$ & $17657(21.2)$ & $1774(20.1)$ & \\
\hline 3 4/week & 375 (3.2) & $6242(5.4)$ & $4972(6.9)$ & $6465(7.8)$ & $635(7.2)$ & \\
\hline Every day & $282(2.4)$ & $3385(2.9)$ & $2202(3.1)$ & $2618(3.1)$ & $240(2.7)$ & \\
\hline
\end{tabular}

Data are presented as number (\%) or mean $\pm \mathrm{SD}$

Abbreviations: BMI, body mass index; TB, tuberculosis; DM, diabetes mellitus.

https://doi.org/10.1371/journal.pone.0195104.t001

diagnosis of TB between January 1, 2002 and December 31, 2006. Additionally, 102 patients with HIV infection were excluded. Finally, 301,081 individuals aged 20-89 years in 2007 without TB before 2007 were enrolled. On the basis of BMI, 4.0\%, 39.8\%, 24.7\%, 28.5\%, and 3.0\% of patients were in the BMI category of $<18.5,18.5-22.9,23-24.9,25-29.9$, and $\geq 30 \mathrm{~kg} / \mathrm{m}^{2}$, respectively. Baseline characteristics of cohort are presented in Table 1.

\section{Effect of BMI on the risk of incident TB}

Total person-years of follow-up was 1,919,106 person-year for the TB outcome. Overall mortality among different BMI groups was not different between high BMI groups (S1 Table). Among 301,081 individuals, 3,772 (1.26\%) incident TB cases were detected. Types of TB are presented in S2 Table. The incidence rate of the event was 19.65 per 10,000 person-years. Development of TB was decreased as BMI was increased, being $2.1 \%$ for $<18.5 \mathrm{~kg} / \mathrm{m} 2,1.6 \%$ for $18.5-22.9 \mathrm{~kg} / \mathrm{m} 2,1.1 \%$ for $23-24.9 \mathrm{~kg} / \mathrm{m} 2,0.8 \%$ for $25-29.9 \mathrm{~kg} / \mathrm{m} 2$, and $0.7 \%$ for $\geq 30 \mathrm{~kg} /$ $\mathrm{m}^{2}(P<0.001)$. There was no difference in the interval between BMI measurement and TB occurrence between BMI groups. Compared with those whose BMI was in the normal range $\left(18.5-22.9 \mathrm{~kg} / \mathrm{m}^{2}\right)$, a dose-dependent relationship between BMI and risk of TB was observed in the whole population after adjusting for age, sex, household income, smoking status, alcohol use, and diabetes, with the risk of TB was lower in overweight or obese individuals (Table 2). Risk of developing TB for participants with BMI $\geq 30 \mathrm{~kg} / \mathrm{m}^{2}$ was nearly 2.5 -fold lower than those with normal BMI (adjusted hazard ratio [aHR], 0.40; 95\% CI, 0.30-0.54). 
Table 2. Effect of BMI on development of tuberculosis and subgroup analysis.

\begin{tabular}{|c|c|c|c|c|c|c|c|}
\hline & BMI category $\left(\mathrm{kg} / \mathrm{m}^{2}\right)$ & Cases & Incidence rate (person-years) & Crude HR (95\% CI) & P-value & aHR (95\% CI) & P-value \\
\hline \multirow[t]{5}{*}{ All } & $<18.5$ & 257 & 73645.7 & $1.43(1.23-1.67)$ & $<.0001$ & $1.36(1.16-1.61)$ & $0.0002^{*}$ \\
\hline & 18.5 to 22.9 & 1893 & 757521.9 & 1 (Reference) & & 1 (Reference) & \\
\hline & 23 to 24.9 & 839 & 477851.1 & $0.64(0.59-0.71)$ & $<.0001$ & $0.63(0.57-0.69)$ & $<0.0001^{*}$ \\
\hline & 25 to 29.9 & 720 & 551784.0 & $0.46(0.41-0.51)$ & $<.0001$ & $0.45(0.40-0.50)$ & $<0.0001^{*}$ \\
\hline & $\geq 30$ & 63 & 58303.2 & $0.40(0.30-0.53)$ & $<.0001$ & $0.40(0.30-0.54)$ & $<0.0001^{*}$ \\
\hline \multicolumn{8}{|l|}{ Age } \\
\hline \multirow[t]{5}{*}{ Age $<50$ years } & $<18.5$ & 109 & 55001.6 & $1.23(0.97-1.55)$ & 0.0834 & $1.20(0.93-1.54)$ & $0.1541^{*}$ \\
\hline & 18.5 to 22.9 & 781 & 480985.9 & 1 (Reference) & & 1 (Reference) & \\
\hline & 23 to 24.9 & 241 & 249777.3 & $0.58(0.49-0.68)$ & $<.0001$ & $0.54(0.45-0.65)$ & $<0.0001^{*}$ \\
\hline & 25 to 29.9 & 199 & 273823.1 & $0.43(0.36-0.51)$ & $<.0001$ & $0.40(0.33-0.49)$ & $<0.0001^{*}$ \\
\hline & $\geq 30$ & 19 & 31991.8 & $0.39(0.24-0.65)$ & 0.0002 & $0.31(0.17-0.54)$ & $<0.0001^{*}$ \\
\hline \multirow[t]{5}{*}{ Age $\geq 50$ years } & $<18.5$ & 148 & 18644.1 & $1.62(1.33-1.98)$ & $<.0001$ & $1.46(1.18-1.82)$ & $0.0007^{*}$ \\
\hline & 18.5 to 22.9 & 1112 & 276535.9 & 1 (Reference) & & 1 (Reference) & \\
\hline & 23 to 24.9 & 598 & 228073.8 & $0.68(0.61-0.76)$ & $<.0001$ & $0.69(0.61-0.78)$ & $<0.0001^{*}$ \\
\hline & 25 to 29.9 & 521 & 277961.0 & $0.47(0.42-0.53)$ & $<.0001$ & $0.48(0.43-0.55)$ & $<0.0001^{*}$ \\
\hline & $\geq 30$ & 44 & 26311.4 & $0.41(0.29-0.58)$ & $<.0001$ & $0.48(0.34-0.68)$ & $<0.0001^{*}$ \\
\hline \multicolumn{8}{|l|}{ Sex } \\
\hline \multirow[t]{5}{*}{ Male } & $<18.5$ & 142 & 22699.7 & $1.76(1.44-2.15)$ & $<.0001$ & $1.54(1.23-1.93)$ & $0.0002^{\dagger}$ \\
\hline & 18.5 to 22.9 & 1072 & 352431.1 & 1 (Reference) & & 1 (Reference) & \\
\hline & 23 to 24.9 & 498 & 284072.4 & $0.58(0.51-0.65)$ & $<.0001$ & $0.57(0.50-0.65)$ & $<0.0001^{\dagger}$ \\
\hline & 25 to 29.9 & 430 & 346054.6 & $0.43(0.38-0.49)$ & $<.0001$ & $0.44(0.39-0.51)$ & $<0.0001^{\dagger}$ \\
\hline & $\geq 30$ & 20 & 31821.1 & $0.28(0.17-0.45)$ & $<.0001$ & $0.24(0.14-0.42)$ & $<0.0001^{\dagger}$ \\
\hline \multirow[t]{5}{*}{ Female } & $<18.5$ & 115 & 50946.0 & $1.17(0.92-1.47)$ & 0.1961 & $1.15(0.91-1.47)$ & $0.2415^{\dagger}$ \\
\hline & 18.5 to 22.9 & 821 & 405090.8 & 1 (Reference) & & 1 (Reference) & \\
\hline & 23 to 24.9 & 341 & 193778.8 & $0.74(0.64-0.86)$ & $<.0001$ & $0.74(0.64-0.86)$ & $<0.0001^{\dagger}$ \\
\hline & 25 to 29.9 & 290 & 205729.4 & $0.51(0.43-0.60)$ & $<.0001$ & $0.48(0.40-0.57)$ & $<0.0001^{\dagger}$ \\
\hline & $\geq 30$ & 43 & 26482.1 & $0.60(0.42-0.85)$ & 0.0047 & $0.61(0.42-0.88)$ & $0.0073^{\dagger}$ \\
\hline \multicolumn{8}{|l|}{$\mathrm{DM}$} \\
\hline \multirow[t]{5}{*}{ Non-DM } & $<18.5$ & 252 & 72838.6 & $1.43(1.23-1.67)$ & $<.0001$ & $1.37(1.16-1.61)$ & $0.0002^{\ddagger}$ \\
\hline & 18.5 to 22.9 & 1818 & 740707.2 & 1 (Reference) & & 1 (Reference) & \\
\hline & 23 to 24.9 & 779 & 461670.7 & $0.63(0.57-0.69)$ & $<.0001$ & $0.62(0.56-0.69)$ & $<0.0001^{*}$ \\
\hline & 25 to 29.9 & 657 & 527883.4 & $0.45(0.40-0.50)$ & $<.0001$ & $0.44(0.39-0.49)$ & $<0.0001^{\text {\# }}$ \\
\hline & $\geq 30$ & 53 & 54932.7 & $0.36(0.26-0.49)$ & $<.0001$ & $0.35(0.25-0.50)$ & $<0.0001^{\text {F }}$ \\
\hline \multirow[t]{5}{*}{ With DM } & $<18.5$ & 5 & 807.1 & $1.49(0.54-4.12)$ & 0.447 & $0.76(0.18-3.12)$ & $0.6978^{\ddagger}$ \\
\hline & 18.5 to 22.9 & 75 & 16814.7 & 1 (Reference) & & 1 (Reference) & \\
\hline & 23 to 24.9 & 60 & 16180.5 & $0.92(0.62-1.35)$ & 0.6605 & $0.82(0.54-1.24)$ & $0.3478^{*}$ \\
\hline & 25 to 29.9 & 63 & 23900.6 & $0.63(0.43-0.93)$ & 0.0199 & $0.64(0.42-0.95)$ & $0.0281^{*}$ \\
\hline & $\geq 30$ & 10 & 3370.5 & $0.87(0.43-1.76)$ & 0.697 & $1.05(0.51-2.15)$ & $0.8901^{*}$ \\
\hline \multicolumn{8}{|l|}{ Smoking status } \\
\hline \multirow[t]{5}{*}{ Never smoker } & $<18.5$ & 147 & 53139.3 & $1.17(0.95-1.44)$ & 0.1317 & $1.19(0.97-1.47)$ & $0.0951^{\S}$ \\
\hline & 18.5 to 22.9 & 1165 & 496978.3 & 1 (Reference) & & 1 (Reference) & \\
\hline & 23 to 24.9 & 516 & 291286.7 & $0.65(0.57-0.73)$ & $<.0001$ & $0.63(0.56-0.71)$ & $<0.0001^{\S}$ \\
\hline & 25 to 29.9 & 443 & 325135.6 & $0.45(0.40-0.52)$ & $<.0001$ & $0.44(0.39-0.50)$ & $<0.0001^{\S}$ \\
\hline & $\geq 30$ & 44 & 35411.1 & $0.42(0.30-0.59)$ & $<.0001$ & $0.42(0.30-0.60)$ & $<0.0001^{\S}$ \\
\hline
\end{tabular}


Table 2. (Continued)

\begin{tabular}{|c|c|c|c|c|c|c|c|}
\hline & BMI category $\left(\mathrm{kg} / \mathrm{m}^{2}\right)$ & Cases & Incidence rate (person-years) & Crude HR $(95 \% \mathrm{CI})$ & P-value & aHR $(95 \% \mathrm{CI})$ & P-value \\
\hline \multirow[t]{5}{*}{ Former smoker } & $<18.5$ & 2 & 1474.3 & $0.57(0.14-2.35)$ & 0.434 & $0.59(0.14-2.45)$ & $0.4666^{\S}$ \\
\hline & 18.5 to 22.9 & 58 & 24723.3 & 1 (Reference) & & 1 (Reference) & \\
\hline & 23 to 24.9 & 36 & 22538.7 & $0.61(0.38-0.98)$ & 0.0426 & $0.61(0.37-0.98)$ & $0.0417^{\S}$ \\
\hline & 25 to 29.9 & 30 & 28120.0 & $0.46(0.28-0.77)$ & 0.0029 & $0.46(0.28-0.76)$ & $0.0027^{\S}$ \\
\hline & $\geq 30$ & 2 & 2303.7 & $0.57(0.14-2.34)$ & 0.4309 & $0.57(0.14-2.38)$ & $0.4442^{\S}$ \\
\hline \multirow[t]{5}{*}{ Current smoker } & $<18.5$ & 69 & 13595.0 & $1.86(1.40-2.46)$ & $<.0001$ & $1.89(1.43-2.50)$ & $<0.0001^{\mathrm{S}}$ \\
\hline & 18.5 to 22.9 & 470 & 168653.7 & 1 (Reference) & & 1 (Reference) & \\
\hline & 23 to 24.9 & 192 & 113651.9 & $0.64(0.53-0.77)$ & $<.0001$ & $0.63(0.52-0.76)$ & $<0.0001^{\S}$ \\
\hline & 25 to 29.9 & 158 & 137238.8 & $0.46(0.38-0.57)$ & $<.0001$ & $0.46(0.38-0.56)$ & $<0.0001^{\S}$ \\
\hline & $\geq 30$ & 11 & 15078.8 & $0.34(0.18-0.66)$ & 0.0015 & $0.34(0.18-0.66)$ & $0.0015^{\S}$ \\
\hline \multicolumn{8}{|l|}{ Alcohol use } \\
\hline \multirow[t]{5}{*}{ Never } & $<18.5$ & 152 & 41499.6 & $1.43(1.17-1.75)$ & 0.0005 & $1.37(1.11-1.68)$ & $0.0038^{\|}$ \\
\hline & 18.5 to 22.9 & 1008 & 397568.0 & 1 (Reference) & & 1 (Reference) & \\
\hline & 23 to 24.9 & 473 & 236440.6 & $0.70(0.62-0.80)$ & $<.0001$ & $0.69(0.61-0.78)$ & $<0.0001^{\|}$ \\
\hline & 25 to 29.9 & 383 & 268232.4 & $0.47(0.41-0.54)$ & $<.0001$ & $0.46(0.40-0.53)$ & $<0.0001^{\|}$ \\
\hline & $\geq 30$ & 38 & 30257.7 & $0.41(0.28-0.60)$ & $<.0001$ & $0.42(0.29-0.62)$ & $<0.0001^{\|}$ \\
\hline \multirow[t]{5}{*}{$2 \sim 3 /$ month } & $<18.5$ & 30 & 15840.3 & $1.04(0.68-1.59)$ & 0.8588 & $0.93(0.59-1.47)$ & $0.7671^{\|}$ \\
\hline & 18.5 to 22.9 & 309 & 149967.2 & 1 (Reference) & & 1 (Reference) & \\
\hline & 23 to 24.9 & 108 & 87165.2 & $0.55(0.42-0.7)$ & $<.0001$ & $0.51(0.39-0.68)$ & $<0.0001^{\|}$ \\
\hline & 25 to 29.9 & 106 & 95196.5 & $0.47(0.37-0.61)$ & $<.0001$ & $0.44(0.33-0.58)$ & $<0.0001^{\|}$ \\
\hline & $\geq 30$ & 7 & 9469.0 & $0.32(0.13-0.77)$ & 0.0107 & $0.27(0.1-0.74)$ & $0.0103^{\|}$ \\
\hline \multirow[t]{5}{*}{$1 \sim 2 /$ week } & $<18.5$ & 30 & 10416.2 & $1.42(0.92-2.17)$ & 0.1102 & $1.20(0.73-1.95)$ & $0.4708^{\|}$ \\
\hline & 18.5 to 22.9 & 284 & 129144.5 & 1 (Reference) & & 1 (Reference) & \\
\hline & 23 to 24.9 & 124 & 94726.4 & $0.54(0.42-0.68)$ & $<.0001$ & $0.57(0.44-0.73)$ & $<0.0001^{\|}$ \\
\hline & 25 to 29.9 & 120 & 114275.7 & $0.42(0.33-0.54)$ & $<.0001$ & $0.45(0.35-0.58)$ & $<0.0001^{\|}$ \\
\hline & $\geq 30$ & 10 & 11423.7 & $0.42(0.21-0.84)$ & 0.0148 & $0.48(0.23-0.97)$ & $0.0397^{\|}$ \\
\hline \multirow[t]{5}{*}{$3 \sim 4 /$ week } & $<18.5$ & 16 & 2156.8 & $2.57(1.46-4.52)$ & 0.0011 & $2.72(1.51-4.92)$ & $0.0009^{\|}$ \\
\hline & 18.5 to 22.9 & 131 & 39530.1 & 1 (Reference) & & 1 (Reference) & \\
\hline & 23 to 24.9 & 63 & 31908.7 & $0.58(0.41-0.83)$ & 0.0023 & $0.61(0.42-0.87)$ & $0.0073^{\|}$ \\
\hline & 25 to 29.9 & 42 & 41678.6 & $0.33(0.22-0.48)$ & $<.0001$ & $0.31(0.21-0.48)$ & $<0.0001^{\|}$ \\
\hline & $\geq 30$ & 4 & 4076.3 & $0.47(0.17-1.27)$ & 0.1336 & $0.38(0.12-1.20)$ & $0.1000^{\|}$ \\
\hline \multirow[t]{5}{*}{ Every day } & $<18.5$ & 21 & 1572.7 & $2.01(1.13-3.59)$ & 0.0175 & $1.73(0.91-3.29)$ & $0.0975^{\|}$ \\
\hline & 18.5 to 22.9 & 98 & 20463.9 & 1 (Reference) & & 1 (Reference) & \\
\hline & 23 to 24.9 & 39 & 13908.9 & $0.72(0.47-1.08)$ & 0.1135 & $0.67(0.42-1.05)$ & $0.0785^{\|}$ \\
\hline & 25 to 29.9 & 43 & 16694.7 & $0.67(0.44-1.01)$ & 0.0571 & $0.62(0.39-0.97)$ & $0.0367^{\|}$ \\
\hline & $\geq 30$ & 2 & 1502.4 & $0.50(0.12-2.03)$ & 0.3283 & $0.54(0.13-2.22)$ & $0.3915^{\|}$ \\
\hline
\end{tabular}

Abbreviations: BMI, body mass index; DM, diabetes mellitus.

*Adjusted by sex, household income, smoking status, alcohol use, and diabetes

${ }^{\dagger}$ Adjusted by age, household income, smoking status, alcohol use, and diabetes

${ }^{\ddagger}$ Adjusted by age, sex, household income, smoking status, alcohol use

${ }^{\S}$ Adjusted by age, sex, household income, alcohol use, and diabetes

"Adjusted by age, sex, household income, smoking status, and diabetes

https://doi.org/10.1371/journal.pone.0195104.t002

\section{Subgroup analysis according to age and sex}

When stratified according to age $<$ or $\geq 50$ years of age, overweight and obesity was associated with reduced a risk of incident TB. For subjects $<50$ years of age, the HR decreased as BMI 
Table 3. Effect of BMI: Subgroup analysis by sex and age.

\begin{tabular}{|c|c|c|c|c|c|c|c|}
\hline & BMI category $\left(\mathrm{kg} / \mathrm{m}^{2}\right)$ & Cases & Incidence rate (person-years) & Crude HR (95\% CI) & P-value & aHR $(95 \% \mathrm{CI})^{*}$ & P-value \\
\hline \multicolumn{8}{|l|}{ Male } \\
\hline \multirow[t]{5}{*}{ Age $<50$ years } & $<18.5$ & 50 & 13473.6 & $2.07(1.48-2.9)$ & $<.0001$ & $1.77(1.22-2.56)$ & 0.0028 \\
\hline & 18.5 to 22.9 & 400 & 222239.6 & 1 (Reference) & & 1 (Reference) & \\
\hline & 23 to 24.9 & 172 & 171368.7 & $0.53(0.43-0.65)$ & $<.0001$ & $0.53(0.42-0.65)$ & $<0.0001$ \\
\hline & 25 to 29.9 & 150 & 212613.6 & $0.37(0.30-0.46)$ & $<.0001$ & $0.37(0.29-0.47)$ & $<0.0001$ \\
\hline & $\geq 30$ & 9 & 23528.0 & $0.24(0.12-0.49)$ & $<.0001$ & $0.17(0.07-0.41)$ & $<0.0001$ \\
\hline \multirow[t]{5}{*}{ Age $\geq 50$ years } & $<18.5$ & 92 & 9226.1 & $1.64(1.27-2.10)$ & 0.0001 & $1.44(1.08-1.91)$ & 0.0122 \\
\hline & 18.5 to 22.9 & 672 & 130191.5 & 1 (Reference) & & 1 (Reference) & \\
\hline & 23 to 24.9 & 326 & 112703.6 & $0.60(0.52-0.70)$ & $<.0001$ & $0.60(0.51-0.71)$ & $<0.0001$ \\
\hline & 25 to 29.9 & 280 & 133441.0 & $0.46(0.39-0.54)$ & $<.0001$ & $0.49(0.42-0.58)$ & $<0.0001$ \\
\hline & $\geq 30$ & 11 & 8293.1 & $0.31(0.16-0.60)$ & 0.0005 & $0.33(0.16-0.66)$ & 0.0018 \\
\hline \multicolumn{8}{|l|}{ Female } \\
\hline \multirow[t]{5}{*}{ Age $<50$ years } & $<18.5$ & 59 & 41528.0 & $0.93(0.68-1.29)$ & 0.6774 & $0.93(0.67-1.30)$ & 0.6718 \\
\hline & 18.5 to 22.9 & 381 & 258746.3 & 1 (Reference) & & 1 (Reference) & \\
\hline & 23 to 24.9 & 69 & 78408.6 & $0.61(0.46-0.82)$ & 0.0009 & $0.59(0.44-0.80)$ & 0.0007 \\
\hline & 25 to 29.9 & 49 & 61209.5 & $0.53(0.38-0.75)$ & 0.0003 & $0.52(0.37-0.75)$ & 0.0004 \\
\hline & $\geq 30$ & 10 & 8463.8 & $0.81(0.40-1.63)$ & 0.5494 & $0.77(0.36-1.63)$ & 0.4957 \\
\hline \multirow[t]{5}{*}{ Age $\geq 50$ years } & $<18.5$ & 56 & 9418.0 & $1.53(1.10-2.13)$ & 0.0114 & $1.51(1.07-2.13)$ & 0.0185 \\
\hline & 18.5 to 22.9 & 440 & 146344.5 & 1 (Reference) & & 1 (Reference) & \\
\hline & 23 to 24.9 & 272 & 115370.2 & $0.80(0.68-0.96)$ & 0.0131 & $0.81(0.68-0.97)$ & 0.0203 \\
\hline & 25 to 29.9 & 241 & 144520.0 & $0.52(0.43-0.62)$ & $<.0001$ & $0.48(0.40-0.58)$ & $<0.0001$ \\
\hline & $\geq 30$ & 33 & 18018.4 & $0.56(0.37-0.85)$ & 0.0066 & $0.59(0.39-0.89)$ & 0.0126 \\
\hline
\end{tabular}

Abbreviations: BMI, body mass index.

*Adjusted by household income, smoking status, alcohol use, and diabetes

https://doi.org/10.1371/journal.pone.0195104.t003

increased. However, in individuals $\geq 50$ of age and older, the HR was not different between participants with BMI 25 to $29.9 \mathrm{~kg} / \mathrm{m}^{2}$ (aHR, $0.48 ; 95 \%$ CI, $0.43-0.55$ ) and $\geq 30 \mathrm{~kg} / \mathrm{m}^{2}$ (aHR, $0.48,95 \%$ CI, 0.34-0.68). Additionally, among same BMI categories, the risk of development of TB in individuals $<50$ years of age was lower compared those 50 years of age and older.

When stratified by sex, the risk of TB decreased as BMI increased, and those with BMI $>30 \mathrm{~kg} / \mathrm{m}^{2}$ had the lowest risk of TB in the male cohort. Compared to males with normal BMI, there was $76 \%$ risk reduction effect of incident TB in males with BMI $>30 \mathrm{~kg} / \mathrm{m}^{2}$ (aHR, 0.24 ; $95 \%$ CI, 0.14-0.42). In contrast, in the female cohort, those with BMI $25-29.9 \mathrm{~kg} / \mathrm{m}^{2}$ had the lowest risk of TB (aHR, 0.48 ; 95\% CI, 0.40-0.57).

When stratified by both age and sex, inverse dose-response relationship was evident between BMI and risk of TB both in males and females above 50 years of age (Table 3 ). However, in female $<50$ years of age, those with BMI $>30 \mathrm{~kg} / \mathrm{m}^{2}$ did not show a protective effect of TB (aHR, 0.77; 95\% CI, 0.36-1.63).

\section{Subgroup analysis according to diabetes}

Subgroup analysis was performed according to presence or absence of DM. In participants without diabetes, risk of TB was decreased as BMI increased. However, in participants with DM, the risk of tuberculosis was significantly lower in those with BMI $25-29.9 \mathrm{~kg} / \mathrm{m}^{2}$, compared with those with normal BMI. A BMI $>30 \mathrm{~kg} / \mathrm{m}^{2}$ was not a protective factor of incident TB in participants with DM (aHR, 1.05; 95\% CI, 0.51-2.15). 
Table 4. Effect of BMI: Subgroup analysis by sex and smoking status.

\begin{tabular}{|c|c|c|c|c|c|c|c|}
\hline & BMI category $\left(\mathrm{kg} / \mathrm{m}^{2}\right)$ & Cases & Incidence rate (person-years) & Crude HR (95\% CI) & P-value & aHR $(95 \% \mathrm{CI})^{*}$ & P-value \\
\hline \multicolumn{8}{|l|}{ Male } \\
\hline \multirow[t]{5}{*}{ Never-smokers } & $<18.5$ & 83 & 10029.8 & $1.95(1.49-2.56)$ & $<.0001$ & $1.95(1.48-2.58)$ & $<0.0001$ \\
\hline & 18.5 to 22.9 & 576 & 173654.0 & 1 (Reference) & & 1 (Reference) & \\
\hline & 23 to 24.9 & 281 & 152939.2 & $0.56(0.47-0.65)$ & $<.0001$ & $0.54(0.46-0.64)$ & $<0.0001$ \\
\hline & 25 to 29.9 & 246 & 186246.4 & $0.41(0.34-0.49)$ & $<.0001$ & $0.41(0.35-0.49)$ & $<0.0001$ \\
\hline & $\geq 30$ & 10 & 15594.0 & $0.24(0.12-0.48)$ & $<.0001$ & $0.19(0.08-0.41)$ & $<0.0001$ \\
\hline \multirow[t]{5}{*}{ Ever-smokers } & $<18.5$ & 59 & 12669.9 & $1.57(1.16-2.12)$ & 0.0036 & $1.57(1.16-2.12)$ & 0.0036 \\
\hline & 18.5 to 22.9 & 496 & 178777.1 & 1 (Reference) & & 1 (Reference) & \\
\hline & 23 to 24.9 & 217 & 131133.1 & $0.61(0.51-0.73)$ & $<.0001$ & $0.61(0.51-0.73)$ & $<0.0001$ \\
\hline & 25 to 29.9 & 184 & 159808.2 & $0.46(0.38-0.55)$ & $<.0001$ & $0.46(0.38-0.55)$ & $<0.0001$ \\
\hline & $\geq 30$ & 10 & 16227.1 & $0.32(0.17-0.63)$ & 0.0008 & $0.32(0.17-0.62)$ & 0.0007 \\
\hline \multicolumn{8}{|l|}{ Female } \\
\hline \multirow[t]{5}{*}{ Never-smokers } & $<18.5$ & 103 & 48546.6 & $1.04(0.81-1.34)$ & 0.7357 & $1.06(0.82-1.36)$ & 0.6594 \\
\hline & 18.5 to 22.9 & 789 & 390490.9 & 1 (Reference) & & 1 (Reference) & \\
\hline & 23 to 24.9 & 330 & 188721.3 & $0.74(0.64-0.86)$ & $<.0001$ & $0.74(0.64-0.86)$ & $<0.0001$ \\
\hline & 25 to 29.9 & 286 & 200178.9 & $0.51(0.44-0.60)$ & $<.0001$ & $0.49(0.42-0.58)$ & $<0.0001$ \\
\hline & $\geq 30$ & 40 & 25326.7 & $0.58(0.40-0.83)$ & 0.0034 & $0.60(0.42-0.87)$ & 0.0068 \\
\hline \multirow[t]{5}{*}{ Ever-smokers } & $<18.5$ & 12 & 2399.4 & $4.14(1.95-8.76)$ & 0.0002 & $4.16(1.96-8.85)$ & 0.0002 \\
\hline & 18.5 to 22.9 & 32 & 14599.9 & 1 (Reference) & & 1 (Reference) & \\
\hline & 23 to 24.9 & 11 & 5057.4 & $0.81(0.32-2.04)$ & 0.6498 & $0.80(0.31-2.02)$ & 0.6291 \\
\hline & 25 to 29.9 & 4 & 5550.6 & $0.34(0.10-1.18)$ & 0.0895 & $0.34(0.10-1.17)$ & 0.0864 \\
\hline & $\geq 30$ & 3 & 1155.4 & $1.24(0.29-5.41)$ & 0.7731 & $1.23(0.28-5.36)$ & 0.7878 \\
\hline
\end{tabular}

Abbreviations: BMI, body mass index.

*Adjusted by age, household income, alcohol use, and diabetes

https://doi.org/10.1371/journal.pone.0195104.t004

\section{Subgroup analysis according to smoking status and alcohol use}

Stratification based on smoking status showed that risk of TB was decreased as BMI increased in all subgroups. When stratified by both sex and smoking status, risk of developing TB for male never-smoker with BMI $\geq 30 \mathrm{~kg} / \mathrm{m}^{2}$ was nearly 5 -fold lower than those with normal BMI (aHR, 0.19; 95\% CI, 0.08-0.41) (Table 4, S3 Table). In ever-smoker males, risk of developing TB for those with BMI $\geq 30 \mathrm{~kg} / \mathrm{m}^{2}$ was nearly 3-fold lower than those with normal BMI (aHR, 0.32 ; $95 \%$ CI, 0.17-0.62). Ever-smoker females with low BMI $<18.5 \mathrm{~kg} / \mathrm{m}^{2}$ had the highest risk for developing TB (aHR, 4.16; 95\% CI, 1.96-8.85).

Stratification based on alcohol use was performed. There were trends to decreased risk of TB with increased BMI in all subgroups.

\section{Discussion}

Our results suggest that higher BMI might be a protective factor of the development of TB, with inverse dose-response relationship between BMI and incident TB. However, very high BMI $\left(\geq 30 \mathrm{~kg} / \mathrm{m}^{2}\right)$ did not reduce the risk of incident TB in young females and participants with DM in this Korean population.

Previous epidemiologic data support the view that obesity might be a protective factor of incident TB [2-5]. An association between BMI and incident TB has been reported in diverse populations. Leung et al. [2] reported that obesity is associated with a lower risk of active TB in elderly people $>65$ years of age in Hong Kong. Cegielski et al. [4] reported that incidence rate 
and risk of incident TB were decreased as BMI increased in a United States cohort. Additionally, they reported that persons who were overweight, had thick fat, or had large muscles had only one-third to one-fifth the risk of TB as people with normal values for these measures. A systematic review reported a log-linear inverse relationship between $\mathrm{TB}$ incidence and BMI, within the BMI range of $18.5-30 \mathrm{~kg} / \mathrm{m}^{2}$ [3].

The protective effect of high BMI on TB might be due to altered immunity. Adipocytes release adipocytokines, which cause the interaction between adipose tissue, inflammation, and immunity [15]. Roth et al. [16] reported that individuals with higher visceral fat release higher amount of tumor necrosis factor (TNF) and other pro-inflammatory markers, which provide an advantage to protect TB. TNF- $\alpha$ is a critical immune mediator in protection against and pathology of TB [17], which has been illustrated by patients who receive TNF antagonist [18]. Furthermore, the adipocyte-macrophage groupings behave like an endocrine gland, releasing TNF, leptin, and other messenger molecules into the circulation, which is capable of influencing host cells and microbes throughout the body, and perhaps providing a protective effect of TB [19]. Anuradha et al. [20] also suggested that the modulation of protective and regulatory cytokines might underlie the protective effect of higher BMI against the development of active TB. Additionally, human visceral adipose tissue has a larger quantity of $\mathrm{T}$ lymphocytes per gram in obese subjects [21]. Because the adaptive immune response mediated by $\mathrm{T}$ cells is critical for control of TB infection in humans [22], T lymphocytes in adipose tissue might affect development of TB.

However, it is uncertain whether very high BMI, especially BMI $\geq 30 \mathrm{~kg} / \mathrm{m}^{2}$, is protective factors of incident TB. A log-linear inverse relationship between TB incidence and BMI was reportedly uncertain for BMI $\geq 30 \mathrm{~kg} / \mathrm{m}^{2}$ [3]. Additionally, Zhang et al. [8] reported that BMI exceeding $28 \mathrm{~kg} / \mathrm{m}^{2}$ was independently associated with host susceptibility of TB in rural China.

Our study suggests that high BMI is associated with a low risk of incident TB. However, not all subgroups showed this inverse dose-response relationship between BMI and risk of incident TB. Interestingly, there was a sex-specific effect of BMI on incident TB. In males, incident TB was more sensitive to BMI, compared with females. The risk of incident TB decreased as BMI increased, and the lowest risk group was males with BMI $>30 \mathrm{~kg} / \mathrm{m}^{2}$. In contrast, although females with high BMI displayed a reduced risk of incident TB, the lowest risk group was those with BMI of $25-29.9 \mathrm{~kg} / \mathrm{m}^{2}$. Additionally, when we stratified for sex and age, $\mathrm{BMI}>30 \mathrm{~kg} / \mathrm{m}^{2}$ did not reduce incident TB in females under 50 years of age; some may be premenopausal women. The risk of incident TB in females $\geq 50$ years of age, who are expected to be postmenopausal, was similar to males concerting sensitivity to BMI.

The results indicate that the effect of BMI on risk reduction of incident TB might be sensitive in males and postmenopausal females. This age- and sex-specific difference of BMI effect might be caused by hormonal differences. It has been reported that testosterone, the primary male sex hormone, impairs macrophage activation and could play a detrimental role in TB [23]. Bini et al. also demonstrated that male mice are more susceptible to TB than female mice, and that this finding was prevented by castration, suggesting that testosterone could be a TB susceptibility factor. Since increased fat mass has been associated with low testosterone [24, 25], high BMI could decrease the risk of incident TB in males. Additionally, in postmenopausal women, as ovarian production of sex hormones declines, the main source of these hormones is from the adrenal glands, with peripheral conversion into their active form in adipose tissue [26]. This might cause different effect of BMI on incident TB between females under and over 50 years of age. Furthermore, Ilavska et al. showed that a sex-dependent association between BMI and white blood cell subpopulation counts in peripheral blood, which reflecting strong 
association between BMI and human immune response [27]. This study can provide one of explanation of sex-specific BMI effect on incident TB in our study.

Our study also showed that the effect of BMI on reduced risk of incident TB was different between individual with and without DM. In diabetics, high BMI was not a protective factor of incident TB. DM itself was a risk factor of TB, and increased as BMI increased. Glycemic control level of each individual also might affect the results. Leung et al. reported that diabetic subjects with hemoglobin A1c $<7 \%$ at enrollment were not at increased risk [28].

The strength of our study is that it was nationwide population-based study including the largest number of study population compared with previous studies. Furthermore, we performed stratification analyses based on various subgroups. Additionally, there was time lag between record of latest BMI and diagnosis of TB based on ICD-10 code. Moreover, overall mortality between high BMI groups was evaluated in our study. It could be argued that difference of overall mortality among different BMI groups would be a confounding factor as high BMI is associated with increased mortality [11]. However, we demonstrated that overall mortality between high BMI groups was not different (S1 Table).

However, there were some limitations. First of all, this study was retrospective study. In addition, BMI does not distinguish between adipose fat, muscle, bone, and water. Further study using methods that could distinguish fat would be instructive. Third, we could not evaluate hormonal levels or $\mathrm{HbAlc}$ because we used insurance claim data. Finally, we could not clarify exact underlying pathophysiology of the effect of BMI on reduced risk of incident TB. More research is needed to elucidate the pathophysiology, focusing on TB and alteration of immune response according to BMI.

\section{Conclusion}

In conclusion, overweight and obesity might be protective factors of the development of $\mathrm{TB}$, with an inverse dose-response relationship between BMI and incident TB. However, very high BMI of $\geq 30 \mathrm{~kg} / \mathrm{m}^{2}$ did not reduced risk of TB in some subgroup including young female and participants with DM in this Korean population.

\section{Supporting information}

S1 Table. Representation for comparison of proportion of occurrence of death by BMI. (DOCX)

S2 Table. Proportion of tuberculosis subtype.

(DOCX)

S3 Table. Subgroup analysis by sex and smoking status. (DOCX)

\section{Author Contributions}

Conceptualization: Soo Jung Kim, Shinhee Ye, Eunhee Ha, Eun Mi Chun.

Data curation: Soo Jung Kim, Shinhee Ye, Eunhee Ha, Eun Mi Chun.

Formal analysis: Soo Jung Kim, Shinhee Ye, Eunhee Ha, Eun Mi Chun.

Investigation: Soo Jung Kim, Shinhee Ye, Eun Mi Chun.

Methodology: Soo Jung Kim, Shinhee Ye, Eunhee Ha, Eun Mi Chun.

Project administration: Eunhee Ha, Eun Mi Chun. 
Supervision: Eun Mi Chun.

Validation: Eunhee Ha, Eun Mi Chun.

Visualization: Soo Jung Kim, Shinhee Ye, Eunhee Ha, Eun Mi Chun.

Writing - original draft: Soo Jung Kim, Eun Mi Chun.

Writing - review \& editing: Soo Jung Kim, Shinhee Ye, Eunhee Ha, Eun Mi Chun.

\section{References}

1. Cegielski JP, McMurray DN. The relationship between malnutrition and tuberculosis: evidence from studies in humans and experimental animals. Int J Tuberc Lung Dis. 2004; 8(3):286-98. PMID: 15139466.

2. Leung CC, Lam TH, Chan WM, Yew WW, Ho KS, Leung G, et al. Lower risk of tuberculosis in obesity. Arch Intern Med. 2007; 167(12):1297-304. https://doi.org/10.1001/archinte.167.12.1297 PMID: 17592104.

3. Lonnroth $\mathrm{K}$, Williams BG, Cegielski $\mathrm{P}$, Dye C. A consistent log-linear relationship between tuberculosis incidence and body mass index. Int J Epidemiol. 2010; 39(1):149-55. https://doi.org/10.1093/ije/ dyp308 PMID: 19820104.

4. Cegielski JP, Arab L, Cornoni-Huntley J. Nutritional risk factors for tuberculosis among adults in the United States, 1971-1992. American journal of epidemiology. 2012:kws007.

5. Yen YF, Hu HY, Lee YL, Ku PW, Lin IF, Chu D, et al. Obesity/overweight reduces the risk of active tuberculosis: a nationwide population-based cohort study in Taiwan. International journal of obesity (2005). 2017; 41(6):971-5. Epub 2017/03/11. https://doi.org/10.1038/ijo.2017.64 PMID: 28280271.

6. Dooley KE, Chaisson RE. Tuberculosis and diabetes mellitus: convergence of two epidemics. The Lancet Infectious diseases. 2009; 9(12):737-46. Epub 2009/11/21. https://doi.org/10.1016/S1473-3099 (09)70282-8 PMID: 19926034

7. Falagas ME, Kompoti M. Obesity and infection. The Lancet Infectious diseases. 2006; 6(7):438-46. Epub 2006/06/23. https://doi.org/10.1016/S1473-3099(06)70523-0 PMID: 16790384.

8. Zhang H, Li X, Xin H, Li H, Li M, Lu W, et al. Association of Body Mass Index with the Tuberculosis Infection: a Population-based Study among 17796 Adults in Rural China. Scientific Reports. 2017; 7.

9. Region WWP. International Association for the Study of Obesity, and International Obesity Taskforce: The Asian-Pacific Perspective: Redefining Obesity and Its Treatment. Geneva, Switzerland, WHO Western Pacific Region. 2000.

10. Oh SW. Obesity and metabolic syndrome in Korea. Diabetes \& metabolism journal. 2011; 35(6):561-6.

11. Oh SW, Shin S, Yun YH, Yoo T, Huh BY. Cut-off Point of BMI and Obesity-Related Comorbidities and Mortality in Middle-Aged Koreans. Obesity research. 2004; 12(12):2031-40. https://doi.org/10.1038/ oby.2004.254 PMID: 15687405

12. Bates MN, Khalakdina A, Pai M, Chang L, Lessa F, Smith KR. Risk of tuberculosis from exposure to tobacco smoke: a systematic review and meta-analysis. Arch Intern Med. 2007; 167(4):335-42. Epub 2007/02/28. https://doi.org/10.1001/archinte.167.4.335 PMID: 17325294.

13. Imtiaz S, Shield KD, Roerecke M, Samokhvalov AV, Lonnroth K, Rehm J. Alcohol consumption as a risk factor for tuberculosis: meta-analyses and burden of disease. The European respiratory journal. 2017; 50(1). Epub 2017/07/15. https://doi.org/10.1183/13993003.00216-2017 PMID: 28705945

14. Jeon $\mathrm{CY}$, Murray MB. Diabetes mellitus increases the risk of active tuberculosis: a systematic review of 13 observational studies. PLoS medicine. 2008; 5(7):e152. Epub 2008/07/18. https://doi.org/10.1371/ journal.pmed.0050152 PMID: 18630984

15. Tilg $\mathrm{H}$, Moschen AR. Adipocytokines: mediators linking adipose tissue, inflammation and immunity. Nature reviews Immunology. 2006; 6(10):772-83. Epub 2006/09/26. https://doi.org/10.1038/nri1937 PMID: 16998510.

16. Roth J. Evolutionary speculation about tuberculosis and the metabolic and inflammatory processes of obesity. Jama. 2009; 301(24):2586-8. Epub 2009/06/25. https://doi.org/10.1001/jama.2009.930 PMID: 19549976.

17. Dorhoi A, Kaufmann SH. Tumor necrosis factor alpha in mycobacterial infection. Seminars in immunology. 2014; 26(3):203-9. Epub 2014/05/14. PMID: 24819298.

18. Wallis RS. Tumour necrosis factor antagonists: structure, function, and tuberculosis risks. The Lancet Infectious diseases. 2008; 8(10):601-11. Epub 2008/10/17. https://doi.org/10.1016/S1473-3099(08) 70227-5 PMID: 18922482. 
19. Fantuzzi G. Tuberculosis and the inflammatory processes of obesity in human evolution. Jama. 2009; 302(16):1754; author reply -5. Epub 2009/10/29. https://doi.org/10.1001/jama.2009.1514 PMID: 19861665.

20. Anuradha R, Munisankar S, Bhootra Y, Dolla C, Kumaran P, Babu S. High body mass index is associated with heightened systemic and mycobacterial antigen-Specific pro-inflammatory cytokines in latent tuberculosis. Tuberculosis (Edinburgh, Scotland). 2016; 101:56-61. Epub 2016/11/21. https:// doi.org/10.1016/j.tube.2016.08.004 PMID: 27865399.

21. Kaminski DA, Randall TD. Adaptive immunity and adipose tissue biology. Trends in immunology. 2010; 31(10):384-90. Epub 2010/09/08. https://doi.org/10.1016/j.it.2010.08.001 PMID: 20817556

22. Jasenosky LD, Scriba TJ, Hanekom WA, Goldfeld AE. T cells and adaptive immunity to Mycobacterium tuberculosis in humans. Immunological reviews. 2015; 264(1):74-87. Epub 2015/02/24. https://doi.org/ 10.1111/imr.12274 PMID: 25703553.

23. Bini El, Mata Espinosa D, Marquina Castillo B, Barrios Payan J, Colucci D, Cruz AF, et al. The influence of sex steroid hormones in the immunopathology of experimental pulmonary tuberculosis. PloS one. 2014; 9(4):e93831. Epub 2014/04/12. https://doi.org/10.1371/journal.pone.0093831 PMID: 24722144

24. Kelly DM, Jones TH. Testosterone and obesity. Obesity reviews: an official journal of the International Association for the Study of Obesity. 2015; 16(7):581-606. Epub 2015/05/20. https://doi.org/10.1111/ obr.12282 PMID: 25982085.

25. Cao J, Chen TM, Hao WJ, Li J, Liu L, Zhu BP, et al. Correlation between sex hormone levels and obesity in the elderly male. The aging male: the official journal of the International Society for the Study of the Aging Male. 2012; 15(2):85-9. Epub 2012/03/29. https://doi.org/10.3109/13685538.2012.666585 PMID: 22452321.

26. Danley J, Kwait R, Peterson DD, Sendecki J, Vaughn B, Nakisbendi K, et al. Normal estrogen, but low dehydroepiandrosterone levels, in women with pulmonary Mycobacterium avium complex. A preliminary study. Annals of the American Thoracic Society. 2014; 11(6):908-14. Epub 2014/06/26. https:// doi.org/10.1513/AnnalsATS.201312-422OC PMID: 24963545.

27. Ilavska S, Horvathova M, Szabova M, Nemessanyi T, Jahnova E, Tulinska J, et al. Association between the human immune response and body mass index. Human immunology. 2012; 73(5):480-5. Epub 2012/03/20. https://doi.org/10.1016/j.humimm.2012.02.023 PMID: 22426256.

28. Leung CC, Lam TH, Chan WM, Yew WW, Ho KS, Leung GM, et al. Diabetic control and risk of tuberculosis: a cohort study. Am J Epidemiol. 2008; 167(12):1486-94. https://doi.org/10.1093/aje/kwn075 PMID: 18400769. 